\title{
Migrações e periferias: o levante do slam
}

\author{
Migrations and peripheries: the rise of slam poetry \\ Migraciones y periferias: la revuelta del slam
}

Fernanda Vilar

\section{Resumo}

Este artigo trata, de maneira comparada, da prática de poesia performática slam presente nas periferias de alguns países da Europa e o Brasil. Observam-se as preocupações contíguas das comunidades marginalizadas e como exprimem de modo poético sua forma de ocupar um lugar no mundo. Apoiado em conceitos como terceira diáspora (Guerreiro, 2010) e artivismo (Debord, 1997), entre outros, o artigo busca entender como essas comunidades afirmam suas alteridades nas dinâmicas das migrações e póscolonizações, assim como reclamam versões alternativas à narrativa oficial e sua inscrição no presente.

Palavras-chave: poesia slam, periferia, migrações, artivismo.

\section{Abstract}

This article compares the practice of slam performance poetry in the peripheries of some European countries with slam performances in Brazil. We note the contiguous concerns of marginalized communities and how they express poetically their way of occupying a place in the world. Based on concepts such as the third diaspora (Guerreiro, 2010) and artivism (Debord, 1997), among others, this article analyzes how these communities affirm their alterities in the dynamics of migration and post-colonization, as well as their claim for alternative versions of the official narrative and its inscription in the present.

Keywords: slam poetry, periphery, migrations, artivism.

\section{Resumen}

Este artículo trata, de manera comparada, de la práctica de la poesía performática slam presente en las periferias de algunos países de Europa y Brasil. Se observan las preocupaciones contiguas de las comunidades marginadas y la manera como expresan de modo poético su forma de ocupar un lugar en el mundo. Basado en conceptos como la tercera diáspora (Guerreiro, 2010) y el artivismo (Debord, 1997), entre otros, el artículo busca comprender cómo estas comunidades afirman sus alteridades en las dinámicas de las migraciones y post-colonizaciones, así como reclaman versiones alternativas a la narrativa oficial y su inscripción en el presente.

Palabras-clave: poesia slam, periferia, migraciones, artivismo.

\section{Artes, periferias e levantes}

O espaço urbano das grandes capitais europeias é habitado por pessoas de diversas origens geográficas que vivem, sobretudo, em suas periferias. Dessa relação social e geográfica desigual, emergem demandas que devem ser tratadas com urgência para evitarmos a (re)produção de novas formas de colonialidade (Quijano, 2005).

Na França, Bélgica e Brasil, países tratados neste artigo, os artistas cujas famílias são provenientes da periferia contestam a maneira subalterna como são tratados. Esses artistas expressam-se de diversas maneiras e por diferentes formas, sobressaindo uma arte engajada politicamente e que hoje encontra novos meios e plataformas de divulgação a que tem sido dado o nome de "artivismo".

\footnotetext{
* Doutora em Literatura Comparada da África Subsaariana e pesquisadora do grupo Memoirs da Universidade de Coimbra, Coimbra, Portugal. (Dorcid.org/0000-0002-7708-5060. E-mail: fernanda.vilars@ gmail.com
} 
O neologismo "artivismo" foi introduzido nos anos 1960 para dar conta das manifestações contra a guerra do Vietnam, assim como dos movimentos estudantis e de contracultura. Nesse sentido, Guy Debord teorizou sobre o situacionismo em seu livro A sociedade do espetáculo (1997), em que apontava para a necessidade da superação da política e da arte, para sabotar as diretrizes do capitalismo e, assim, dar um novo saber à arte e, por conseguinte, à vida. É apenas em meados de 1990, com a revolução da internet, que o termo artivismo volta a aparecer no vocabulário crítico para ilustrar não apenas uma prática de arte política, mas para reavaliar o que se considera política e arte, numa reatualização do conceito de Debord (1997). Dessa prática conectada emerge o conceito de terceira diáspora, trabalhado por Goli Guerreiro (2010a) para explicar os intercâmbios culturais que ocorrem nas geografias atlânticas e do sul global. Nesse contexto, é importante ressaltar que a questão de fundo é a transformação do capital em espetáculo, de onde deriva em seguida a problemática da arte.

Neste artigo pretendemos discutir num primeiro momento as periferias e sua relação com as migrações e o colonialismo, assim como sua expressão nas artes e literatura. Em seguida, apresentaremos o conceito de artivismo e de combarte para designar formas de artes engajadas no contexto da terceira diáspora. Finalmente, trataremos de uma forma de artivismo muito corrente nas sociedades periféricas contemporâneas: o levante da poesia slam em diferentes geografias e as similitudes de suas denúncias contra novas formas de exclusão e colonialidades, funcionando como uma ágora para o debate político contemporâneo.

\section{As periferias na literatura}

No legado dos estudos pós-coloniais, houve uma preocupação global em revisitar a história daqueles que foram deixados nas margens por longo período, sendo esquecidos ou desprezados. A criação de um espaço para debater as periferias é um assunto que está em voga nos últimos 30 anos, especialmente no olhar que se coloca sobre o sul global e, mais atualmente, nas relações Sul-Sul.

Segundo Roberto Vecchi (2004, p. 221), as periferias existem não apenas como um lugar, mas sobretudo porque há uma relação entre dois polos que estão vinculados de maneira desigual. Portanto, a periferia existe enquanto elemento que se situa em oposição a outro elemento determinado - o centro. O termo "periferia" deriva do grego peri, que significa "em torno" e pherein, que significa "levar". No contexto urbano contemporâneo, a população que habita esses locais está também estereotipada de acordo com uma relação de percepção díspar: geralmente são racializadas como não brancas e inserem-se num sistema que lhes dificulta a inserção dentro dos parâmetros e privilégios acordados às populações que estão no centro.

Nas periferias é frequente haver comunidades distintas cujo elo comum é a precariedade financeira e uma história de migrâncias. Entre os fatores que causam esse movimento em direção às periferias podemos citar o êxodo rural, ou seja, migrações internas muitas vezes de causa econômica. No caso brasileiro, vários elementos do passado se conjugam para designar as periferias: desde o escravocrata colonial e o indígena até os retirantes nordestinos, e atualmente migrantes da América Latina e alguns africanos. Já no caso europeu, a migração provinda dos antigos territórios coloniais são as mais marcantes faces das periferias recentes que agora crescem com a chegada dos refugiados de guerra, como os sírios. Nas periferias, a segregação espacial e social não é anódina, mas resultado de um produto urbanista cuja ideologia é higienista. ${ }^{1}$ Como defende o jornalista Xavier de Jarcy em seu recente livro Les abandonnés: histoire des "cités de banlieue" (2019), a criação das periferias obedece a uma lógica em que o cidadão desaparece, dando lugar à coletivização da habitação e uma estereotipização de seus habitantes - tornando-os uma espécie de "abandonados" da sociedade.

A literatura registra diferentes facetas dessa relação desigual que se fabrica para produzir diferentes formas de dominação. Um clássico da literatura brasileira, o romance naturalista $O$

\footnotetext{
${ }^{1}$ No início do século XX, o prefeito do Rio de Janeiro, Pereira Passos, inspira-se no projeto urbanístico de Paris instaurado pelo Barão de Haussmann - ambos criaram multidões de deslocados não realocados. A falta de planejamento urbano obrigou as pessoas a construírem cabanas - o que ainda hoje formam as favelas no Brasil e é visível nas periferias europeias nos acampamentos de refugiados.
} 
cortiço, publicado em 1890 por Aloísio de Azevedo, descreve como viviam nos finais do século XIX as pessoas que não possuíam meios econômicos suficientes para uma vida confortável num Rio de Janeiro infestado de cortiços. Atualmente, a literatura continua sendo testemunha do falhanço da segregação nas periferias. $\mathrm{O}$ autor franco-argelino Mehdi Charef revisita em seu livro autobiográfico Rue des Pâquerettes (2019) o que foi ser um morador das periferias parisinas na década de 1960. Devido às precárias condições dos casebres feitos de madeira, sem nenhum saneamento básico ou equipamentos para o inverno, ele se lembra de ter vergonha de estar onde está ("J'ai honte d'être là où je suis"). A poesia de W-Black (2018) sobre o Morro da Providência, considerada a primeira favela do Brasil, formada por exescravizados e ex-combatentes de Canudos, revela igualmente os falsos sonhos daqueles que migram e se instalam em periferias no desejo de liberdade: "a favela só nasceu de uma falsa liberdade que devia por fim à escravidão."

Semelhante caso também é retratado no livro Luanda, Lisboa, Paraíso (2018), de Djaimilia Pereira de Almeida. Ela relata como vive uma família angolana que busca tratamentos médicos em Portugal no início dos anos 1980, e que acaba por não retornar. Apesar dos difíceis périplos a passar e as consequências desse mau acolhimento - "[o pai] tinha condenado o filho a não ter história por medo de que ele não se conseguisse erguer se a conhecesse" -, é muito comum que a primeira geração de migrantes esconda suas origens e eduque seus filhos na tradição do país escolhido para viver. Apesar desse esforço de ocultação que visa uma melhor integração, a sociedade de acolhimento, via seus racismos estruturais, lembra que essas pessoas não pertencem àquele lugar devido às suas origens. A segunda e terceira gerações começam agora a escrever a história dos pais e reivindicar seu lugar como cidadãos dos países onde nasceram. Esses elementos são comuns nesses relatos que abordam a maneira como são tratadas as pessoas oriundas de classes baixas e o local na sociedade que continua a ser-lhes assignado, além de expor a maneira como a ficção retrata a falta de políticas públicas de inclusão e denunciam as desigualdades que contribuem para a manutenção de um sistema de exploração que atinge os migrantes.

A periferia vem lembrar que grande parte da história moderna da Europa se passou fora de seus limites geográficos, nos territórios que foram colonizados, como podemos ler no notável romance do autor francês Omar Benlaala, Tu n'habiteras jamais Paris (2018). Ao chegar na capital francesa, o pai do autor vai trabalhar na construção civil e é recebido com a frase que dá título ao livro "Você nunca vai morar em Paris". Para contrariar a determinação de seu destino, o pai impõe-se o dever de habitar a cidade que ajuda a reconstruir, apesar de seus conterrâneos aceitarem em sua maioria o destino das periferias. No Brasil, a literatura também vem marcar os fluxos migratórios internos, como o clássico romance Vidas Secas, de Graciliano Ramos, e atualmente a resistência da periferia, iniciada já na década de 1960 com Carolina Maria de Jesus, ganha novo fôlego pelas vozes literárias de Rodrigo Ciríaco, Ferréz, Marcelino Freire e Conceição Evaristo, entre outras vozes emergentes que são oriundas de diversas vagas de migrações internas no país.

Seja na Europa ou no Brasil, as periferias registam a perpetuação das segregações sociais, raciais e habitacionais do imaginário colonial. Essa herança continua a invisibilizar uma população muitas vezes étnica e religiosamente marcada, gerando ambientes de exclusão e de racismo que não são discutidos como questões urgentes de políticas públicas. Nesses dois diferentes contextos é importante observar como as práticas urbanas e periféricas de arte são importantes como veículos de expressão de demandas urgentes dessas populações - e que não se restringem apenas determinados países ou comunidades - são questões transnacionais. Nas periferias nascem novas formas de combarte, em que a iniciativa artística combina-se com dinâmicas de combate, criando diversas formas de levante: movimentos localizados de protesto que formam por instantes um lugar por onde vão começando a ser tratados temas sérios para o desenvolvimento humano, econômico, social e atualmente, ambiental. A arte engajada torna-se o espaço da utopia e de comunicação para ideias e ideais de futuro, como veremos a seguir. 


\section{O combarte periférico}

As artes não são inocentes, pois refletem a realidade e podem se transformar em arautos de mudança. É o caso das artes engajadas das periferias que emergem de maneira enfática a partir dos anos 1980 e ganham uma dimensão extraterritorial com o advento da internet. Existem diversos exemplos de movimentos artísticos que articularam a estética com ensejo de mudança social e política, como bem explica Rui Mourão:

Muito embora seja a partir da Modernidade que de forma mais profunda se implantam contraculturas de dissensão e subversão artística em relação a lógicas hegemônicas, há toda uma tradição multissecular de crítica criativa ao status quo (em particular nas artes performativas, onde desde os primórdios do teatro na Antiga Grécia a sátira se impôs). Ainda assim, as conexões entre arte e agitação política intensificam-se sobretudo a partir do séc. XX (Goldberg 2007: 7), primeiro com as chamadas vanguardas históricas (por via de movimentos como o Futurismo, o Expressionismo, o Construtivismo, o Dadaísmo ou o Surrealismo) e mais tarde com o movimento Hippie ou o Maio de 68, na revolução cultural ocorrida nas décadas de 60 /70 (Mourão, 2015, p. 55).

Dessa maneira, a arte traz à realidade aquilo que a sociedade é incapaz de confrontar, como já advertia o escritor Sony Labou Tansi (1985, p. 11, tradução nossa): “A arte é a força de dizer à realidade o que ela não poderia dizer por seus próprios meios ou, em todo caso, o que ela arriscaria de manter voluntariamente em silêncio". Atualmente assistimos em várias geografias distintas a emergência de extremismos (contra a/o imigrante provindo/a de um país africano, um/a refugiado/a sírio/a, a/o venezuelana/o no Brasil) que transformam o sistema político em território de batalhas. Diante dessas circunstâncias em que o discurso político persiste em se voltar contra o Outro - enquanto bode expiatório de mazelas estruturais da sociedade - surgem novas vozes e gramáticas de ação política, tecnológica, ambiental, espiritual, pelos direitos humanos, igualdade de gênero, entre outros.

Na contramão dessa política de exclusão, o poeta e idealizador do Sarau Cooperifa, Sérgio Vaz (2016), explica: "transformamos a senzala em quilombo" - isto é, a periferia já não é mais dormitório da classe trabalhadora subalterna, mas lugar de encontro e resistência, onde é possível detectar transformações segundo as necessidades da comunidade. Graças às campanhas de escolarização das últimas décadas e à emergência das novas tecnologias e mídias sociais, houve um verdadeiro levante em diversos locais, pois as ideias se multiplicam com mais facilidade, as iniciativas se copiam, as pessoas se correspondem instantaneamente, gerando uma nova dinâmica social que permitiu a emergência de diferentes formas de resistência sendo esse seu lado positivo.

É nesse sentido que a terceira diáspora - teorizada por Goli Guerreiro para pensar os intercâmbios culturais que acontecem a despeito das rotas mainstream da cultura utilizando a web - permite entender o dinamismo proveniente dos setores sociais subalternizados e/ou estigmatizados em diferentes contextos geográficos, sociais e culturais:

o que o circuito de comunicação potencializado pela web traz de mais interessante é exatamente a possibilidade de deslocar centros e periferias, tornando possível escrever um livro em que Salvador é o centro do mundo. Milton Santos ajuda bastante: "o centro do mundo está em todo lugar. O mundo é o que se vê de onde se está" (Guerreiro, 2010, s.p.).

A terceira diáspora é um conceito que permite entender a dinâmica de enfrentamento dos problemas de circulação da arte, sobretudo devido ao racismo de omissão. A arte engajada utiliza inúmeras linguagens e recursos tais como a arte de rua, o vídeo, a música, a performance, a poesia, a net art e a intervenção não apenas para representar a realidade, mas para engajar transformações, mobilizando e inspirando o espectador.

Os projetos artivísticos pensam a dimensão política da arte e cruzam os territórios do protesto social, baseados numa lógica de que a validade da arte só é possível se esta for capaz de transformar situações sociais e históricas politicamente significantes. As/os artistas fazem emergir novos cenários e possibilidades de fruição, de participação e de criação artística ao tomar o espaço urbano. Dessa maneira amplificam, sensibilizam e problematizam para a 
sociedade suas causas e reivindicações sociais. Por exemplo, o artista muralista português Vhils, comovido com o assassinato da vereadora Marielle Franco e de seu motorista no Rio de Janeiro, criou um mural com seu retrato em Lisboa no quadro do projeto "Brave Walls", da organização de defesa dos Direitos Humanos da Amnistia Internacional, para que o crime não seja esquecido e que os responsáveis não saiam impunes (Novo..., 2018).

$\mathrm{O}$ artista ativista situa-se no interior de uma relação social em que é fundamental o reconhecimento das alteridades, assim como a crítica das condições que produzem a contemporaneidade. Na dualidade entre arte e ativismo, a relação entre ética e estética amplia-se e, dessa maneira, o uso de métodos colaborativos e de disseminação dos resultados obtidos permite fazer emergir novas subjetividades e discursos renovados no campo da política. Esse modus operandi possibilita a entrada no debate público de temas que não constam ou têm pouca relevância na agenda dos países no contexto europeu e brasileiro: racismo estrutural, gentrificação de partes da cidade, combate à precariedade, habitação e acolhida de imigrantes e refugiados, entre outros temas. Um exemplo de artivismo e combarte pode ser ilustrado com a poesia slam. Trata-se de uma arte urbana e democrática praticada em diversos lugares do mundo, sobretudo nas periferias, e que permite aos poetas, apenas com sua voz e em três minutos, passar a mensagem daquilo que julgam pertinente lançar como questionamento, como veremos a seguir.

\section{As artes na periferia: o caso do slam}

O slam² é uma prática poética viva e urbana, ligada às periferias. Situado na intersecção entre arte, movimento e momento, essa poesia oral é um dos veículos de expressão das atuais periferias dos grandes centros urbanos. A origem do slam foi identificada nos anos 1980 por Marc Smith, empregado da construção civil e poeta dos subúrbios de Chicago, nos Estados Unidos, que organizava reuniões em bares. Hoje em dia as sessões de slam ocorrem em distintos espaços, sendo o importante ocupar um espaço onde todos possam ler, dizer, improvisar ou recitar um texto diante do público (D'Alva, 2011). A origem da palavra em si vem do o verbo inglês "to slam", que significa bater ou criticar, sendo também utilizado nos torneios esportivos. No caso da poesia slam, as palavras concertadas em poesia, quando enunciadas, funcionam como uma bofetada em quem as escuta durante a competição.

A socióloga norte-americana Susan Somers-Willet, autora do livro The cultural politics of slam poetry: race, identity and the performance of popular verse in America (2009), considera o slam como uma performance identitária marginalizada, permitindo conexões e encontros num espaço cultural aberto. Poesia engajada e engajadora, os slammers têm apenas três minutos em cena, quando toda a energia se concentra e circula pela palavra e pelo gesto. Pessoas escolhidas aleatoriamente no público dão notas às performances para eleger a vencedora ou o vencedor da noite. Após a competição, há a sessão de microfone aberto, onde o público pode também expressar o que quiser, geralmente a partir de um texto preparado previamente. Da página ao palco e da composição à performance, são várias as disciplinas mobilizadas para executar este gênero híbrido e inédito que dá voz a todos que tiverem algo a falar.

O potencial transformador da arte nas periferias das grandes cidades foi narrado no filme Slam, vencedor da Câmara de Ouro do Festival de Cannes de 1998, e realizado pelo documentarista especialista de gangues Marc Levine por Saul Williams, poeta protagonista do filme. O documentário retrata a redução da violência urbana e o poder libertador e reparador da palavra. Esse filme, assim como Slam Nation (1998, de Paul Devlin), foram essenciais para Roberta Estrela D'Alva descobrir o slam e trazê-lo ao Brasil, sendo a Zona Autônoma da Palavra (ZAP!) $)^{3}$ a primeira cena slam brasileira, em 2008. A diversidade do público e dos temas tratados foi o que a atraiu, além de ser um dos raros espaços de cultura gratuitos, como registra

\footnotetext{
${ }^{2}$ As poesias slam citadas aqui foram gentilmente cedidas por seus autores ou então capturadas em vídeos que estão disponíveis online. As traduções do francês ao português foram feitas por mim.

${ }^{3}$ Ver: http://zapslam.blogspot.com
} 
o documentário Slam: voz de levante (2018), ${ }^{4}$ dirigido por Estrela D'Alva e Tatiana Lohmann, que traça a trajetória do slam, dentro e fora do Brasil, e a evolução de diversos poetas. Segundo Lohmann: "O slam é uma ferramenta de organização de comunidade, de exercício da cidadania, de liberdade de expressão, lugar de encontro que não depende de nada, a não ser de pessoas" (Vasconcelos, 2018, s.p.).

A poesia de Mariana Felix expressa o potencial emancipador da arte quando esta corresponde às linguagens e modos de expressão acessíveis ao seu entorno, pois a arte de rua tira a poesia de seu locus elitista e transforma-se em material artístico e de protesto:

Bem-vindos todos à aula de rua!

Respeita a luta!

E a poesia marginal explica:

Foi o Hip Hop,

E não os decassílabos dos lusíadas,

Que fez muito moleque

que hoje escreve,

Enfim parar de cheirar cocaína.

A descoberta do slam pelo artista-slammer Hocine Ben ${ }^{5}$ dá-se também pelo filme de Levin. Graças à chegada do hip-hop e artes de rua nas periferias de Paris, Hocine soube que havia uma arte que não era feita e destinada apenas às elites, como ele revela em um de seus poemas:

84 ? Eu descubro hip hop e eu entendo a mensagem.

Eu confronto a polícia e descubro a mestiçagem.

Integra-te a ti, eu não preciso de cura.

A França é o meu país, a Argélia é a minha terra! (Ben, 2017)

A arte de rua deu as ferramentas para Hocine buscar na história de sua família e das pessoas de seu bairro, assim como nos arquivos e livros, as fontes de inspiração para sua arte e escapar ao destino traçado dos jovens da periferia, filhos da imigração. Numa entrevista ao grupo de pesquisa Memoirs, ele afirma que, dentro de casa, e mesmo no bairro, ele se compreendia em outro território, que não era a França. Nessa geografia da exclusão em que há uma barreira física (estrada) que separa o bairro da cidade, os moradores se confinam: "mesmo se eu nunca tenha tido passagem na prisão, recebi a pena perpétua em liberdade", desabafa no Facebook. Esse sentimento é compartilhado igualmente pelo poeta Sérgio Vaz, que compara os habitantes das periferias aos navegantes que achavam que o mundo acabava no além mar. Esses dois relatos explicam a dinâmica de isolamento que domina o imaginário e cerceia a liberdade daqueles que moram nas periferias, espelhado na falta de transporte público ou na precariedade financeira, entre outros fatores. A cena slam vem exatamente quebrar esse isolamento. Ao organizar os Saraus da Cooperifa, já no início dos anos 2000, Vaz convida a cidade para ver a arte da periferia, um movimento pioneiro para a emergência da possibilidade da arte de transformar as possibilidades de futuros das pessoas da periferia. A periferia entra em cena numa dinâmica distinta da lógica hierárquica das artes "centrais", conforme anuncia o site da Cooperifa: "é quando a poesia desce do pedestal e beija os pés da comunidade". ${ }^{6}$ Gênero irmanado com a poesia dos saraus, o slam encontrou seu espaço sobretudo entre os jovens e permitiu que as mulheres também pudessem competir nessa cena.

A maior presença feminina (cis e trans) nas cenas de slam é revelador de sua capacidade de ultrapassar barreiras e agregar diferentes temas, origens e gerações para o fazer poético. De acordo com as slammers belgas Lisette Lombé e Joelle Sambi, se o rap e o hip-hop são artes em que há um predomínio do gênero masculino, o slam é a arte urbana onde as mulheres

\footnotetext{
${ }^{4}$ Slam: voz de levante ganhou o prêmio especial do júri e de melhor documentário no $19^{\circ}$ Festival do Rio, além de ser eleito o melhor filme nacional no Festival Internacional de Mulheres no Cinema (2018).

${ }^{5}$ O documentário Slam - Ce que nous brûle, de Pascal Tessaud, retrata quatro slammers franceses: Nëggus, Luciole, Hocine Ben e Julien Delmaire. Para mais informações sobre Hocine Ben e sobre seu percurso, assim como sua experiência no Brasil, ler Ben (2011).

${ }^{6}$ Disponível em: http://cooperifa.com.br
} 
encontram mais conforto e acolhimento para se expressar. ${ }^{7}$ No Brasil há cenas de slam apenas para mulheres, como o "Slam das minas", que tem Luz Ribeiro como uma de suas fundadoras. Para ela o importante é ser ouvida, pois a periferia sempre teve voz, mas não quem a escutasse: "Sempre fui muito invisível. Cada vez que eu subo, falo 3 minutos e alguém me ouve [...] eu me sinto menos invisível." A cena belga também está repleta de mulheres de todos os horizontes: Joy concentra sua poesia na condição da mulher migrante e deseja a representação das mulheres em sua diversidade, para que cada uma tenha sua palavra a dizer. ${ }^{8}$ A cena slam, quando reservada apenas às mulheres permite criar um lugar de segurança para futuras batalhas. Reflexo disso é o grande número de mulheres nos campeonatos mundiais, 11 dos 20 competidores na Copa do Mundo de Slam 2018 que ocorreu em Paris eram mulheres.

Ao analisar o slam feito pelas e para as periferias de diferentes centros urbanos, podemos observar uma cartografia rica e complexa das rotas artísticas e culturais que se constituem independentemente do "centro" e sem tê-lo como oposição ou espelho. Diferentemente das relações desiguais que a periferia entretém com o centro, as rotas criadas são independentes. Por exemplo, várias poesias incluem a recuperação do arquivo colonial mascarado e/ou apagado, e cabe aos poetas reinterpretar, trabalhar contra ou mesmo ignorá-lo, deixando claro que a arte tem o poder de enunciar alternativas críticas e reflexão. Dessa necessidade de manifestar artisticamente temas de relevância social nasce o artivismo e o combarte.

No caso belga, a reapropriação do arquivo colonial dá-se de maneira muito clara no poema "Qui oubliera?" (Quem esquecerá?), de Lisette Lombé (2018). Sua primeira performance resulta de uma agressão racista num trem, quando disseram-lhe: "Neguinha suja, vá aprender a escrever". Ela, que já era professora de francês, fez da ferida uma arma e, utilizando o famoso discurso de independência de Patrice Lumumba, atualizando-o 50 anos depois de sua declamação. O primeiro parágrafo é uma retomada literal de Lumumba, o que serve para denunciar a permanência da mentalidade colonial na sociedade belga contemporânea, que não soube lidar com a migração provinda das colônias e tampouco com sua descendência:

Quem esquecerá?

Que um negro se tratava por $t u \ldots$

É claro, não como a um amigo

Mas porque o você, respeitoso, só estava reservado aos

Brancos.

Quem esquecerá?

[...]

Eles disseram-me

Tu és suja! Neguinha suja!

A tua mãe dormiu com um negro! És uma bastarda!

Eles disseram-me

Deverias voltar para o teu país! Para tua floresta!

Para tua cabana!

Deverias voltar a tua árvore! Teu cipó! Tuas bananas!

Deverias agradecer à Bélgica de te ter acolhido!

Embora tenhas nascido aqui... (Lombé, 2018, p. 8 e 9, tradução nossa).

Ao declamar pela primeira vez o poema, Lisette não dava voz apenas ao seu sofrimento, mas falava em nome de toda uma diáspora colonial, que respondeu ao final de sua performance "Pas nous!" (Nós não!). O slam permite que se fale em nome de um grupo, a partir de experiências pessoais, e que se compartilhe, no presente e em presença, assuntos que devem entrar na ordem do dia. Hocine Ben retoma de maneira mais irônica a falta de um passado

\footnotetext{
${ }^{7}$ Relato obtido durante entrevista feita pelo grupo de pesquisa Memoirs em 13 de março de 2018, Pianofabrik, Bruxelas (material do projeto, não publicado).

8 “J'insiste beaucoup sur la représentation des femmes, notamment les femmes migrantes, les femmes voilées. J'aimerais que chacune ait la parole. J'en fais un combat quotidien. Je suis pour un féminisme qui englobe la femme dans toute sa diversité" (Joy apud Rossius, 2017, s.p.).
} 
colonial nos livros de história franceses, denunciando o papel do Estado nessa política de omissão que acaba por prejudicar a imagem daqueles que habitam as periferias da França:

O mal das palavras se alimenta dos não ditos,

Ausências, silêncios malditos; então

Se os livros de história são muito pesados nas mochilas,

É porque muitas histórias permanecem inconfessáveis.

Quando o Estado apaga, sufoca um caso,

É o povo que ele estrangula e quem digere mal.

Aqui está, encontrei algo revolucionário:

Distribua dicionários em nossos bairros (Ben, 2017, tradução nossa)

No poema de Hocine Ben, assim como no de Lisette Lombé, a falta de reconhecimento da história ultramarina de colonizações dos países europeus revelam o problema persistente de racismo e de não reconhecimento dessas pessoas enquanto europeias, herdeiras de uma história colonial. Nesse sentido, Joy retoma a história para explicar como é dual a experiência daqueles que migraram e dos filhos dessa imigração. Joy é a voz clara da confusão da segunda geração, que nasce no país onde os pais migraram e é confrontada com duas histórias: a da origem dos pais e a de sua origem. A poeta expressa a dificuldade de conseguir se situar entre a vítima e o carrasco colonial, por julgar ser fruto desse encontro:

[...] Somos ao mesmo tempo a raiva merecida de Lumumba quando a África finalmente se atreveu a levantar-se; e o belga que queria sua morte e que, sem barulho, elimina a ameaça. Nós somos ao mesmo tempo os congoleses que são explorados para a colheita de borracha; e a megalomania de um rei e o racismo de seus discursos. Somos, ao mesmo tempo o belga que não queria tudo aquilo, e aquele que não sabia; e o negro que se salvou matando seus irmãos sem desvios. Nós somos a esperança dos anos 60, fome na barriga, dançarinos sob os sóis da independência (Joy, 2015, s.p., tradução nossa).

No mesmo sentido a poesia de Hocine Ben também revela essa dualidade de pertencer a dois mundos, país colonizador e colonizado, além de ser habitante da periferia, como faz no poema "Aubercail":

Dupla nacionalidade, dupla periculosidade, dupla papelada,

Se eu tenho que fazer, onde eu devo ir? Essa integração que incomoda você!

Eu sou francês na França, na Argélia eu sou argelino ...

Mas no meu coração é muito mais simples, eu sou apenas um carinha de Auber, um

Albertivillariano! (Ben, 2005, tradução nossa). ${ }^{9}$

Os temas do slam derivam do cotidiano dos poetas e das questões de atualidade. Refletem em geral as preocupações da sociedade e muitas vezes interrogam alguns de seus tabus - como imigração, racismo, sexismo e colonialismo. O racismo é uma das heranças coloniais mais persistentes e seu antídoto está sendo preparado por esta geração que compreende a riqueza de suas diversas origens e que consegue trabalhar diferentes subjetividades pela afirmação de sua alteridade, como expressa Roberta Estrela D'Alva:

Abrem-se as portas

E a diáspora se levanta

Espanta

A dor, o medo, a dúvida

Desconfianças

Inseguranças,

Complexos de inferioridade

Inconsciência

Esquecimento.

Não dá mais para adiar

A hora é agora

${ }^{9}$ Gentilmente cedido pelo artista à autora do artigo. 


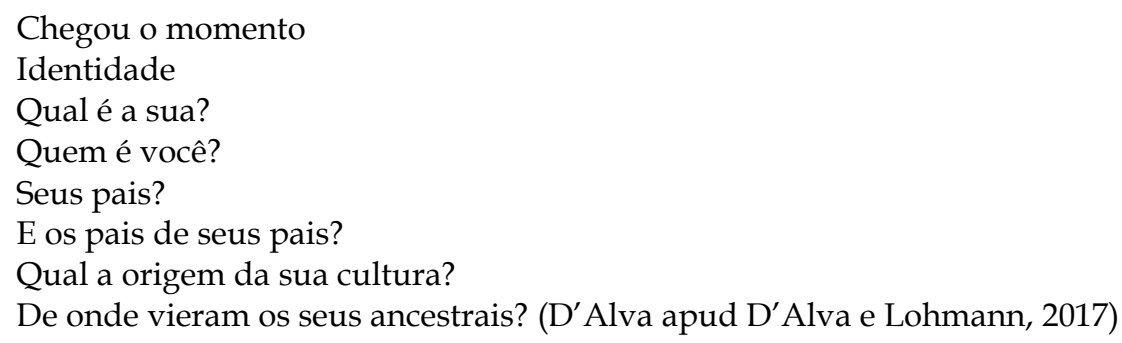

Nesse poema-slam, apresentado na final da Copa Mundial de Slam de 2016, em Paris, Roberta Estrela D'Alva retoma o trauma inaugural das pessoas traficadas e escravizadas no Brasil e que tiveram apagados os traços de seus ancestrais. A quem foram negados qualquer forma de pertença ou identificação que resultaram em séculos de complexos de inferioridade. A denúncia do colonialismo é feita também pela poeta Joëlle Sambi. Ela se manifesta em favor do Congo, apesar dos esforços neocoloniais para transformá-lo em um não lugar, sem histórias e particularidades, como vemos em sua poesia "Congo Eza!", que em lingala quer dizer "o Congo existe":

Nós somos a cólera. A cólera que, de tanto ter sido encolhida se torna implacável. A tragédia encena-se perante a seus olhos. E nada, nada poderá pará-la, porque

O Congo é um país.

Aceite-o com tudo o que ele tem de desprezível de grande de forte. Sim, nossas almas estão à venda. Não, o inferno não existe,

a pena não dura para sempre,

e o mal não tem raízes!

Nós não somos pequenas bombas, inúmeras sub-munições vindas para atormentar seu quotidiano.

Para ver escorrer seu sangue tanto quanto vocês sugam o nosso.

Não, é claro que não (Sambi, 2014, s.p., tradução nossa). ${ }^{10}$

O rapper e slammer francês Kerry James também interroga a herança colonial e seu lugar hoje na sociedade francesa em "Banlieusards":

Eu não sou uma vítima, mas um soldado

Olhe para mim, sou negro e orgulhoso de sê-lo

Manejo a língua de Molière, e domino as letras

Francês porque a França colonizou meus ancestrais

Mas minha mente é livre e minha África não tem dívidas (James, 2008).

O coletivo Congo Eza!, composto por três belgo-congoleses, Lisette Lombé, Joëlle Sambi e o rapper de origem congolesa Badi, afirma em sua performance "À travers l'autre" que ser belgocongolês é "estar sentado com o cu entre duas cadeiras", revelando com esta expressão o desconforto que é viver numa sociedade que não respeita a alteridade. No mesmo sentido, StEthique-Slam manifesta o racismo sofrido e seu antídoto no potencial do slam para evacuar a raiva de ter que ocupar os lugares de exclusão da sociedade francesa:

A França não é racista, mas ...

muitos franceses não gostam dos árabes...

o resultado de uma responsabilidade colonial mal digerida...

após a guerra de independência argelina "apenas siga o carro em frente... "

Assobie, Slam e seu ódio (2016, s.p.)

Tanto Roberta Estrela D'Alva quanto Joelle Sambi, o coletivo Congo Eza!, St-Ethique-Slam, Hocine Ben, Lisette Lombé e Kerry James utilizam a poesia para dizer que os anos que a história negra ficou ignorada se transformará em grito, em cólera, em exigência por reparação: as portas se abriram e o slam tornou-se uma plataforma de arte engajada para revisitar a história e pedir um acerto de contas com o passado para a criação de um futuro melhor. Este é um dos temas que permeiam o slam, por tratar-se de uma arte que fala a partir da periferia, da experiência de

${ }^{10}$ Gentilmente cedido pelo artista à autora do artigo. 
um passado familiar relacionado com a colonização recente no caso europeu ou, como no caso brasileiro, de um passado escravagista colonial.

A ferida fundadora da escravatura que construiu o Brasil é atualizada e revisitada, como manifesta a poesia de Dugueto Shabazz, que compara a situação atual das pessoas negras com a de seus antepassados escravizados e conclui que, no Brasil, apenas modernizaram a subalternidade colonial:

Em 360, ou mais dias por ano, você, você, você, você

Não é brasileiro, é escravo africano!

No baú de gado humano ou no quarto de empregada,

reprodução moderna do tumbeiro e da senzala,

não se eleva quando sobe no "de serviço",

sua situação é preta, consciência de mestiço

pra que? Sermos pardos, mulatos, morenos,

Se afinal é como pretos que vivemos!

Num país que divide, oprime, segrega,

rebaixa, humilha, discrimina e nega! (Shabazz apud D'Alva e Lohmann, 2017).

Apesar de o discurso nacional advogar pelo bem viver em comum, a realidade demonstra que o racismo sofrido pelos pais é perpetuado na existência dos filhos. A transmissão da memória familiar e aquilo que foi transformado em história entram em choque nessas performances artísticas. Essas heranças violentas são tratadas em "Mãe Gentil", da brasileira Luíza Romão, que revisita de maneira crítica a história do Brasil e faz da poesia um grito feminista. Ao analisar as colonialidades que permeiam o imaginário nacional, Luíza Romão remete ao estupro enquanto imagem fundadora da colonização:

Eu queria escrever a palavra Brasil colônia produto perfeito

PAU-BRASIL,

[...]

A COLONIZAÇÃO, ELA COMEÇOU PELO ÚTERO

matas virgens, virgens mortas

A COLONIZAÇÃO FOI UM ESTUPRO!

Deodoro metendo a espada entre as pernas

de uma princesa babel

Pedro ejaculando-se dom precoce

Costa e Silva gemendo cinco vezes

AI AI AI AI AI- AI 5

Getúlio Juscelino Geisel Collor Jânio Sarney

a ordem parte da cabeça do membro ereto

de quem é a favor da redução mas vê vida num feto

é o pau-brasil multiplicado trinta e três vezes

e enfiado numa só garota

eu olho pra caneta e tenho certeza

eu não vou mais escrever o nome desse país

enquanto estupro for prática cotidiana

e o ideal de mulher,

A MÃE GENTIL (Romão apud D'Alva e Lohmann, 2017)

A performance slam provoca no público o desconforto e o questionamento quando aborda temas que não foram tratados de maneira complexa no debate público. Essa cena poética é um local feito pela e para a periferia, criando um espaço onde o público pode identificar-se com os temas e refletir sobre seu percurso e as alteridades. A poesia de Sérgio Vaz também aponta os crimes estruturais da sociedade brasileira:

Porém uma coisa sempre esteve clara, nós, os pobres, negros, índios, nordestinos, não somos bem-vindos neste país.

A não ser que aceitemos as migalhas de sempre.

A menos que aceitemos a escravidão disfarçada de salário mínimo. 
A menos que aceitemos a escravidão disfarçada de salário nenhum.

Tem gente que acha que cantamos ou fazemos poesia porque estamos felizes, satisfeitos com tudo.

Na verdade, da nossa música, do poema, da nossa dança, sai o lamento, o chamado pra luta. É doído de ser excluído dentro de casa.

Por isso muita gente estranha o refrão (Vaz, 2018).

A resistência passa em assumir sua cor de pele, em reconhecer seu valor apesar dos discursos que deformam a percepção do valor de uma pessoa devido a sua origem, que é a base de uma sociedade racista, como evidencia a poesia de Kika Sena:

Tingi tudo de preto

Sou Tição, Tição, Tição

Pós-apocalipto

Brasa forte, pior do que deuses ditadores

Num mexe, num mexe, num mexe,

Comigo não...

Porque à dor, à dor, à dor

Eu sei reagir! (Sena apud D’Alva e Lohmann, 2017)

O slam, como material poético e artístico híbrido, é uma forma de arte que permite o reconhecimento de diferentes formas de saber e de estar no mundo. É uma ferramenta de autodeterminação de comunidades marginalizadas que podem encontrar ouvintes que compartilham os mesmos pesares. Enquanto forma de arte democrática, encontra raramente barreiras: as línguas se misturam, assim como as origens e os gêneros. Como vimos nos exemplos citados, o mal-estar é transformado em lirismo, a estética e a vivência são as fontes do fazer poético. Dessa maneira, os temas ultrapassam fronteiras e, quase sempre, refletem problemas estruturais comuns a diversas sociedades.

\section{O que pode o slam?}

O slam possui um potencial de diálogo e respeito baseado na escuta e apreciação da performance do outro, mesmo que não se concorde com o que é dito. Devido à sua economia de meios, sendo a poesia e a voz os únicos elementos em cena, o slam foi a porta de entrada para outras artes de diversos artistas. Muitos deles, engajados com suas comunidades, fizeram de sua arte uma forma de combarte e de si verdadeiros artivistas.

Apesar de todo seu engajamento, os artivistas sabem que não é o mundo que será mudado, mas, sim, a consciência individual de que nossas ações diárias podem mudar hábitos da sociedade. Por isso, tanto na França quanto no Brasil e na Bélgica, os artistas do slam realizam oficinas de escrita em escolas e instituições públicas. Eles são artistas polivalentes em sua grande maioria, dedicando-se não apenas ao slam, mas participando de projetos de cinema, artes e literatura. Desse modo, o contato dos artistas com os estudantes resulta em práticas de escrita e questionamento que ultrapassam os currículos escolares.

A conexão entre arte e ativismo no slam possibilita aos setores estigmatizados da sociedade uma intervenção política criativa, poética e sensorial. Ao mesmo tempo que vai além das formas tradicionais de ativismo e desobediência, o artivismo abala nossas representações do que é a arte no seu circuito, visibilidade e participação na esfera pública. Nesse sentido, o artivismo é uma expressão que prolonga o sentido de cidadania.

A poesia do slam carrega a mestiçagem cultural e linguística, pois é feita sobretudo por pessoas cuja história deriva dos encontros coloniais. Consideramo-lo um OVNI (objeto verbal não identificado) literário por ter emergido e se afirmado como arte viva e urbana, sem as barreiras tradicionais de validação e legitimação do fazer artístico tradicional - e por ser raramente fixado em livros, sendo apenas um momento de voz e presença. Esse fazer poético floresce com a noção de comunidade, de escuta, além de dar a palavra a todas as pessoas que queiram manifestar-se. Para Roberta Estrela D'Alva, a revolução está em ouvir o que o outro 
tem a dizer: "Olhar outro ser humano falar um poema é muito revolucionário". Talvez devamos escutar mais o que as periferias nos dizem, e como o dizem.

\section{Referências}

ALMEIDA, Djaimilia Pereira de (2018). Luanda, Lisboa, Paraíso. Lisboa: Companhia das Letras.

BEN, Hocine (2005). Aubercail. Poema em vídeo gravado no Théâtre de la Commune, Aubervilliers, out. Disponível em: http://gerflint.fr/Base/Bresil9/Ben_Aubercail2005.mp4. Acesso em: 23 fev. 2019.

BEN, Hocine (2011). D’où tu Slam Hocine Ben. Synergies Brésil, n. 9, São Paulo, p. 113-118.

BEN, Hocine (2017). Le cartable ou l'usine. Sound Cloud. Audio on-line. Disponível em: https:// soundcloud.com/hocine-ben-185108117/le-cartable-et-lusine. Acesso em: 23 fev. 2019.

BENLAALA, Omar (2018). Tu n'habiteras jamais Paris. Paris: Flammarion.

CHAREF, Mehdi (2019). Rue des Pâquerettes. Paris: Hors d'atteinte.

D'ALVA, Roberta Estrela (2011). Um microfone na mão e uma ideia na cabeça - O poetry slam entra em cena. Synergies Brésil, n. 9, São Paulo, p. 119-126.

D’ALVA, Roberta Estrela (2016). Diáspora. Copa do Mundo de Slam, Paris.

D'ALVA, Roberta Estrela; LOHMANN, Tatiana (Dir.) (2017). Slam! A voz do levante. Rio de Janeiro: Globo Filmes. Documentário. 1h35min.

DEBORD, Guy (1997). A sociedade do espetáculo. Tradução de Estela dos Santos Abreu. Rio de Janeiro: Contraponto.

GUERREIRO, Goli (2010a). Terceira diáspora - Culturas negras no mundo atlântico. Salvador: Corrupio.

GUERREIRO, Goli (2010b). A “Terceira Diáspora”: entrevista com Goli Guerreiro. A Tarde, Salvador, 12 nov. Reproduzido no blog pessoal da autora. Disponível em: https://bit.ly/2lYqgj9. Acesso em: 23 fev. 2019.

GUERREIRO, Goli (s.d.). Terceira Diáspora, Salvador. Blog pessoal. Disponível em: http:/ / terceiradiaspora.blogspot.com. Acesso em: 23 fev. 2019.

JAMES, Kerry (2008) Banlieusards. In: JAMES, Kerry. À l'ombre du show business. Produção de Masta, Tefa \& Aledji. Compact Disc. Disponível em: https://genius.com/Kery-james-banlieusards-lyrics Acesso em: 23 fev. 2019.

JARCY, Xavier de (2019). Les abandonnés: histoire des "cités de banlieue". Paris: Albin Michel.

JOY SLAM (Gioia Kayaga) (2015). Génération Lumumba. In: KAYAGA, Gioia. L'arbre sans racines d'un pays sans soleil. Etterbeek: Maelström. O trecho do poema transcrito no artigo foi publicado na Fanpage da poeta no Facebook em 26 jul. 2015. Disponível em: https://bit.ly/354hC4A Acesso em: 23 fev. 2019.

LOMBÉ, Lisette (2018). Black words. Bruxelles: L'Arbre à Paroles.

MOURÃO, Rui (2015). "Performances artivistas: incorporação duma estética de dissensão numa ética de resistência". Cadernos de Arte e Antropologia, v. 4, n. 2. Disponível em: http://cadernosaa.revues.org/938 Acesso em: 23 fev. 2019.

NOVO mural de Vhils no Monsanto é uma homenagem à ativista Marielle Franco (2018). Diário de Notícias, Lisboa, 22 dez. On-line. Disponível em: https://bit.ly/2nMuqv4. Acesso em: 23 fev. 2019.

QUIJANO, Anibal (2005). “Colonialidade do poder, eurocentrismo e América Latina". In: LANDER, Edgardo (Org.). A colonialidade do saber: eurocentrismo e ciências sociais. Perspectivas latino-americanas., Buenos Aires: Clacso. p. 227-278. (Colección Sur Sur).

ROSSIUS, Justine (2017). Rencontre avec Joy, qui exprime ses coups de gueule en slam. Flair, Bruxelles, 22 fev. On-line. Disponível em: https:// bit.ly/2okXgTJ Acesso em: 23 fev. 2019.

SAMBI, Joëlle (2014). Congo Eza. Solola bien. Tumblr da autora. Disponível em: https://joellesambi.tumblr.com/post/73298891634/congo-eza Acesso em: 23 fev. 2019. 
SOMERS-WILLET, Susan (2009). The cultural politics of slam poetry: race, identity and the performance of popular verse in America. Michigan: The University of Michigan Press.

ST-ETHIQUE-SLAM (2016). Slam-ta-haine, Siffle! Mediapart, Paris, 2 jun. On-line. Disponível em: https:// bit.ly/2nVEORP. Acesso em: 23 fev. 2019.

TANSI, Sony Labou (1985). Les sept solitudes de Lorsa Lopez. Paris: Points.

VASCONCELOS, Paloma (2018). Documentário une emoção, território e identidade para falar sobre história do slam. Ponte, São Paulo, 22 nov. On-line. Disponível em: https://bit.ly/2mV6eGZ. Acesso em: 23 fev. 2019.

VAZ, Sérgio (2008). Cooperifa - Antropofagia periférica. Rio de Janeiro: Aeroplano.

VAZ, Sérgio (2016). Arte na Periferia por Sérgio Vaz. Programa Quem Somos Nós?, 17 out. Disponível em: https:/ / www.youtube.com/watch?v=OUNhCWKHiyM. Acesso em: 23 fev. 2019.

VAZ, Sergio (2018). Um inferno chamado Brasil. Fanpage do poeta no Facebook, 20 ago. Disponível em: disponível em https:/ / www.facebook.com/poetasergio.vaz2/posts/1849479728464769 Acesso em: 23 fev. 2019.

VECCHI, Roberto (2004). Periferia/periférico. In: ALBERTAZZI, Silvia; VECCHI, Roberto (Org.). Abecedario postcoloniale I-II. Roma: Quodilibet.

W-BLACK (2018). Morro da Providência. In: FELIPPSEN, Cosme. Memórias do Rio: conheça a história do Morro da Providência. G1 Rio de Janeiro, Programa Bom dia Rio, 22 maio. Disponível em: https://glo.bo/2mXCCbQ Acesso em: 23 fev. 2019. 